\title{
RETRACTED ARTICLE: Quantifying forest stand management intensity in Central European forests
}

\author{
Peter Schall • Christian Ammer
}

Received: 1 February 2012/Revised: 7 August 2012/ Accepted: 7 September 2012/Published online: 6 October 2012

(C) The Author(s) 2012. This article is published with open access at Springerlink.com

The Biodiversity Exploratories are long-term research sites established to advance biodiversity research in Germany. So called core projects provide infrastructure and manage long-term monitoring. From one of these core projects inventory stand data of nearly all forest plots are available.

Unfortunately, we mistakenly believed that these data could be used by the scientific community of the exploratories. Even more unfortunately, we realized not till publication of the online version of our article "Quantifying forest stand management intensity in Central European Forests" that we were not allowed to use the data. We are very sorry for this mistake which was truly unintended and we herewith explicitly apologize for our misunderstanding. Therefore we, the authors Peter Schall and Christian Ammer, retract the article.

We repeated the analysis with data from our own sources and obtained very similar results. The publication can be found at http://dx.doi.org/10.1007/s10342-013-0681-6.

P. Schall · C. Ammer $(\bowtie)$

Department of Silviculture and Forest Ecology of the Temperate

Zones, Georg-August-University Göttingen, Büsgenweg 1,

37077 Göttingen, Germany

e-mail: christian.ammer@forst.uni-goettingen.de 